\title{
OS PRINCÍPIOS DO CONTRADITÓRIO E DA AMPLA DEFESA NAS MEDIDAS DE PROTEÇÃO À LUZ DO ESTATUTO DA CRIANÇA E DO ADOLESCENTE
}

\section{THE PRINCIPLES OF CONTRADITORY AND WIDE DEFENSE IN PROTECTIVE MEASURES IN THE LIGHT OF THE STATUTE OF CHILDREN AND ADOLESCENTS}

Letícia Alves de Oliveira*

\begin{abstract}
RESUMO
O presente trabalho aborda a necessidade de aplicação dos princípios do contraditório e da ampla defesa nas ações de medidas de proteção. Em um primeiro momento, buscar-se-á apresentar o Estado Democrático de Direito e os direitos e garantias constitucionalmente estabelecidas, bem como definir o devido processo legal e os princípios do contraditório e da ampla defesa. Em um segundo momento, construir uma reconstituição da história do direito da criança no Brasil. Ainda, explanar acerca do procedimento das medidas protetivas e suas implicações. Em um terceiro momento, demonstrar-se-á a necessidade do contraditório e da ampla defesa nas medidas protetivas e as consequências da omissão dos princípios no processo. Por fim, o intuito da pesquisa é mostrar a necessidade da aplicação dos direitos constitucionais nos processos de medida protetiva, tendo em vista a gravidade que acarreta às partes a ausência do devido processo legal no processo.
\end{abstract}

Palavras-chave: Medida protetiva. Devido processo legal. Estatuto da criança e do adolescente. Estado Democrático de Direito.

\begin{abstract}
The present work addresses the need to apply the principles of the adversary and the broad defense in the actions of protection measures. In a first moment, it will seek to present the Democratic State of Law and the constitutionally established rights and guarantees, as well as to define the due legal process and the principles of the adversary and the wide defense. In a second step, to build a reconstruction of the history of children's rights in Brazil. Also, explain about the protective measures procedure and its implications. In a third moment, it will be demonstrated the necessity of the adversary and the wide defense in the protective measures and the consequences of the omission of the principles in the process. Finally, the purpose of the research is to show the need for the application of constitutional rights in the processes of protective measures, in view of the gravity that causes the parties to lack due legal process in the process.
\end{abstract}

Keywords: Protective measure. Due legal process. Child and Adolescent Statute. Democratic State of Law.

Artigo submetido em 25 de março de 2020 e aprovado em 22 de fevereiro de 2021.

"Bacharel em Direito pela Pontifícia Universidade Católica de Minas Gerais. E-mail: leticia_alves3m@hotmail.com 


\section{INTRODUÇÃO}

O Estatuto da Criança e do Adolescente, aprovado em 1990, é símbolo da evolução dos direitos referente a Infância e Juventude. A história da criança e do adolescente é marcada pela Doutrina da Situação Irregular, em que somente as crianças que delinquiam ou se encontravam em situação de abandono eram tuteladas pelo direito, segundo Maciel (2017). Com a evolução do direito se estabelece a Doutrina da Proteção Integral na qual a criança e o adolescente passam a ser titulares de direitos e garantias.

Contudo, nas medidas protetivas, ainda há a utilização de preceitos da Doutrina da Situação Irregular. As medidas de proteção são aplicáveis quando há ofensa ou ameaça a direitos das crianças e dos adolescentes. Tal ameaça ou ofensa pode ser praticada pela sociedade, pelo Estado ou pela família. A controvérsia se instaura quando há a necessidade de instauração de um processo que pode ocasionar no afastamento da criança do seu seio familiar. Não há procedimento a ser seguido e nem sequer as partes possuem a oportunidade de se defenderem.

Com o advento da Constituição de 1988, foi estabelecido o Estado Democrático de Direito, que assegura às partes direitos e garantias fundamentais. Assim, como decorrência lógica, surge o processo constitucional que visa garantir às partes o acesso à justiça e a inviolabilidade dos direitos constitucionais. Nasce, assim, o devido processo legal, que estabelece, dentre outras premissas, o princípio do contraditório e da ampla defesa.

Dessa forma, é necessário que as medidas protetivas obedeçam ao devido processo legal, a fim de permitir a participação de todas as partes envolvidas no processo e garantir que o melhor interesse da criança seja atingido.

Nesse intento, o presente estudo é dividido em três capítulos.

O primeiro capítulo pauta na contextualização do Estado Democrático de Direito e nas garantias nele previstas. Ainda, conceituar-se-á o princípio do contraditório e da ampla defesa, com base na Constituição Federal e no Código de Processo Civil.

O segundo capítulo é dedicado a compreender a conquista de direitos da criança e do adolescente. Definir as medidas de proteção, sua necessidade, quando e como deve ser aplicada.

No terceiro capítulo há a junção dos dois capítulos anteriores, em que é possível compreender a necessidade de um procedimento obediente aos princípios constitucionais do contraditório e da ampla defesa.

Por fim, na conclusão serão apresentadas as ponderações finais acerca do tema proposto, bem como o reforço de que há direitos e garantias sendo violados, além de destacar a prática reiterada de aplicação do código de menores, que não se pode consentir em um Estado Democrático de Direito, vez que fere diretamente os direitos e garantias fundamentais garantidos pela Constituição Federal.

\section{O PRINCÍPIO DO CONTRADITÓRIO E DA AMPLA DEFESA}

\subsection{Contextualização}

A Constituição de 1988 estabelece que o Brasil se constitui em um Estado Democrático de Direito que consagra um extenso rol de direitos e garantias fundamentais.

Importante destacar que a Constituição é a lei do Estado, ou seja, o meio pelo qual os direitos e garantias são assegurados. Dessa forma, o Estado Democrático atinge seus objetivos por meio da Constituição que estabelece formas para garantir a efetividade dos direitos e garantias. 
Artigo: Os princípios do contraditório e da ampla defesa nas medidas de proteção à luz do Estatuto da Criança e do Adolescente

Conforme Bretas (2012) a Constituição agrupa os princípios do Estado Democrático, do Estado de Direitos e das normas jurídicas positivadas para configurar o Estado Democrático de Direito.

Dessa forma, o Processo Constitucional é pressuposto lógico para a garantia de um processo justo, em conformidade com o Estado Democrático de Direito. Nele são estabelecidas normas que asseguram o respeito aos direitos e garantias fundamentais previstos na Constituição.

Baracho (2004) estabelece pontos importantes para a compreensão do Processo Constitucional, conforme se verifica

\begin{abstract}
Algumas regras são básicas para a compreensão de pontos essenciais à tutela constitucional do processo: a correta citação (audiatur altera pars), sendo que a falta de citação, nos casos concretos, gera nulidade; inconstitucionalidade por falta do respeito aos prazos; inconstitucionalidade por sonegação do direito de audiência ou de ser ouvido; inconstitucionalidade pela privação de provas, para correção de erros de procedimento; inconstitucionalidade por supressão ou privação de recursos; inconstitucionalidade por privação de revisão judicial; inconstitucionalidade por falta de idoneidade do juiz, pelo que é garantia fundamental a existência de Tribunal competente e imparcial, que não viole a garantia do due process of law. O Processo Constitucional efetiva-se através desses pressupostos, bem como da consagração dos procedimentos que garantem os direitos das partes, outorgando-lhes oportunidade razoável para defender-se e fazer valer suas provas. Em todas essas circunstâncias deve-se assegurar a efetiva igualdade das partes, em todas as fases de atuação no processo. Os princípios do devido processo legal, da defesa em juízo e do acesso à justiça foram elevados à categoria de disposições internacionais. (BARACHO, 2004, p. 71).
\end{abstract}

Portanto, o Processo Constitucional visa assegurar o acesso à justiça, bem como a defesa dos interesses individuais por meio de um processo obediente ao devido processo legal que possibilite a contribuição das partes na formação do convencimento do juízo.

\title{
2.2 Princípio do Contraditório
}

A Constituição de 1988 traz em seu texto a garantia constitucional do devido processo legal. Que, segundo Bretas (2012), deve ser compreendido como

Um bloco aglutinante e compacto de vários direitos e garantias fundamentais e inafastáveis ostentados pelas pessoas nas suas relações com o Estado, quais sejam: a) direito de amplo aceso à jurisdição, prestada pelo Estado dentro de um tempo útil ou lapso temporal razoável; b) garantia do juízo natural; c) garantia do contraditório; d) garantia de plenitude da defesa, com todos os meios e recursos a ela (defesa) inerentes, aí incluído, também, o direito da parte à produção da prova e à presença do advogado ou do defensor público; e) garantia da fundamentação racional das decisões jurisdicionais, com base no ordenamento jurídico vigente (reserva legal); garantia de um processo sem dilações indevidas. (BRETAS, 2012, p. 73).

Verifica-se que o devido processo legal se relaciona com o princípio da legalidade e da legitimidade, pois garante um processo em conformidade com os preceitos constitucionais, devidamente estruturado, com a efetiva tutela de direitos e garantias fundamentais.

Um dos principais princípios decorrentes do devido processo legal é o princípio do contraditório. O princípio do contraditório está previsto na Carta Magna no art.5, LV "aos litigantes, em processo judicial ou administrativo e aos acusados em geral são assegurados o contraditório e a ampla defesa, com os meios e recursos a ela inerentes". 
Foi apenas com a Constituição de 1988 que houve a ampliação da aplicação do princípio do contraditório para os processos judiciais e administrativos. Historicamente a Constituição assegurava que tal princípio deveria ser utilizado tão somente nos processos penais, a fim de beneficiar o acusado.

Dessa forma, há que se definir o que é contraditório na visão do processo civil, sendo ele um instrumento para garantir isonomia as partes para livre convencimento do juízo.

Para Gonçalves (1992)

\begin{abstract}
O contraditório não é apenas 'a participação dos sujeitos do processo'. Sujeitos do processo são o juiz, seus auxiliares, o Ministério Público, quando a lei o exige, e as partes (autor, réu, intervenientes). O contraditório é a garantia de participação, em simétrica paridade, das partes daqueles a quem se destinam os efeitos da sentença, daqueles que são os 'interessados', ou seja, aqueles sujeitos do processo que suportarão os efeitos do provimento e da medida jurisdicional que ele vier a impor. (GONÇALVES, 1992, p. 120).
\end{abstract}

Didier Junior (2015) reforça que o contraditório é reflexo da democracia na estrutura do processo, pois democracia é participação que no processo só se efetiva por meio do contraditório. Ainda, divide o princípio do contraditório em duas garantias: a de participação e possibilidade de influência na decisão.

Sendo assim, Didier Junior (2015) alude que

\begin{abstract}
A garantia da participação é a dimensão formal do princípio do contraditório. Tratase da garantia de ser ouvido, de participar do processo, de ser comunicado, poder falar no processo. Esse é o conteúdo mínimo do princípio do contraditório e concretiza a visão tradicional a respeito do tema. De acordo com esse pensamento, o órgão jurisdicional efetiva a garantia do contraditório simplesmente ao dar ensejo à ouvida da parte. Há, porém, ainda, a dimensão substancial do princípio do contraditório. Trata-se do " poder de influência". Não adianta permitir que a parte simplesmente participe do processo. Apenas isso não é o suficiente para que se efetive o princípio do contraditório. É necessário que se permita que ela seja ouvida, é claro, mas em condições de poder influenciar a decisão do órgão jurisdicional. (DIDIER, 2015, p. 78-79).
\end{abstract}

Infere-se que o princípio do contraditório é a participação no processo, por meio da defesa, oitiva das partes e testemunhas e atuação ativa nos autos. Contudo, apenas a participação não é suficiente, sendo necessário que suas ações tenham o poder de influenciar a decisão do juízo. Isso significa que não basta apenas que seja dada a oportunidade a parte de se manifestar é necessário também que a participação seja tal em que possa influenciar na decisão judicial a ser prolatada.

Outrossim, o Código de Processo Civil estabelece nos art. $7^{\circ}, 9^{\circ}$ e 10 formas de assegurar o princípio do contraditório no processo civil, por meio da paridade de tratamento em relação ao exercício de direitos e faculdades processuais, aos meios de defesa aos ônus, aos deveres e à aplicação de sanções processuais, competindo ao juiz zelar pelo efetivo contraditório. Ademais, estabelece que não será proferida decisão contra uma das partes sem que ela seja previamente ouvida. Por fim, o juiz não pode decidir, em grau algum de jurisdição decisão sem fundamento ao qual as partes tenham a oportunidade de se manifestarem, ainda que a matéria possa ser decidida de ofício. (BRASIL, 2015)

Theodoro Junior (2015) sustenta que incumbe ao julgador consultar as partes antes de formar o seu convencimento sobre a questão a ser decidida. Frisa-se, ainda, que o contraditório visa permitir um diálogo entre juiz e partes, possibilitando não só um procedimento justo como também uma decisão justa. 
Artigo: Os princípios do contraditório e da ampla defesa nas medidas de proteção à luz do Estatuto da Criança e do Adolescente

\title{
2.3 O princípio da ampla defesa
}

O princípio da ampla defesa também está previsto no art. $5^{\circ}$, inciso LV da Constituição Federal e se constitui no "direito da parte de usar todos os meios admitidos em lei para exercer o seu direito de defesa". Assevera Jorge (2007) que

Como no contraditório, a ampla defesa carrega em si prerrogativas, que vão desde a defesa pessoal e a defesa técnica, passando pela acusação clara e precisa, a concessão de tempo e meios adequados para preparação da defesa, até o direito de não ser obrigado a depor contra si. (JORGE, 2007, p. 41).

Observa-se que ambos os princípios se complementam vez que buscam permitir um efetivo acesso à justiça ao estabelecer normas que norteiam a cooperação das partes no processo a fim de influenciarem a decisão judicial, com os meios admitidos para defesa.

Para Morais (2003) a distinção dos princípios se pauta

\begin{abstract}
Por ampla defesa, entende-se o asseguramento que é dado ao réu de condições que lhe possibilitem trazer para o processo todos os elementos tendentes a esclarecer a verdade ou mesmo de omitir-se ou calar-se, se entender necessário, enquanto o contraditório é a própria exteriorização da ampla defesa, impondo a condução dialética do processo (par conditio), pois a todo ato produzido pela acusação, caberá igual direito da defesa de opor-se-lhe ou de dar-lhe a versão que melhor lhe apresente, ou, ainda, de fornecer uma interpretação jurídica diversa daquela feita pelo autor. (MORAIS, 2003, p. 95).
\end{abstract}

A linha que diferencia os princípios é tênue vez que o princípio do contraditório está contido no princípio da ampla defesa. A ampla defesa assegura a parte todos os meios admitidos em direito, enquanto que o contraditório é a participação efetiva no processo.

Ademais, Tavares (2012) esclarece

Também integra a ampla defesa o direito a ser informado da acusação inicial (o que é praticamente um pressuposto para que haja direito de defesa), e de todos os fatos arrolados, assim como do impulso oficial e dos demais atos da outra parte, o que envolve o direito à publicidade ou, no caso de processo sigiloso, o direito de acesso (processo que corra em segredo de Justiça, como algumas questões atinentes ao Direito de Família e menores). (TAVARES, 2012, p. 760).

Em análise aos preceitos estabelecidos, verifica-se que as garantias constitucionais do devido processo legal se transformam em garantia das partes em busca de um processo em que possam cooperar a fim de convencerem o juízo por meio dos atos praticados no curso do processo. Ambas partes prezam pela qualidade da prestação jurisdicional a fim de obter um resultado útil do processo.

No ECA o princípio do contraditório e ampla defesa são concedidos as partes conforme o procedimento adotado. Dessa forma, tendo em vista que as ações de Medidas Protetivas não possuem rito próprio definido em lei deverá ser aplicado o procedimento comum previsto no Código de Processo Civil, bem como os princípios elencados no diploma legal.

\section{AS MEDIDAS DE PROTEÇÃO NO ESTATUTO DA CRIANÇA E DO ADOLESCENTE - ECA}

\subsection{A evolução dos direitos das crianças no Brasil}


Durante o período colonial, a criança não era objeto de proteção do Estado, sendo submetida a todos os tipos de abuso, dentre eles o trabalho infantil. A criança era submetida a autoridade parental e não possuía direitos básicos e mínimos que assegurassem o seu desenvolvimento.

\begin{abstract}
Em regra, a criança se diferenciava do adulto apenas em relação ao tamanho e a força para o trabalho. Não havia as etapas da infância, juventude e fase adulta. Assim que adquiria uma independência mínima como, por exemplo, se alimentar, fazer suas necessidades fisiológicas, trocar a vestimenta sozinha, já era automaticamente misturada aos adultos. Portanto, não havia um critério a ser seguido como o desenvolvimento biológico, o cronológico de idade e, muito menos, o psicológico para determinar o início e o fim das fases da vida. (LIMA, Renata Mantovani de; POLI, Leonardo Macedo; JOSÉ, Fernanda. 2017, pag. 317-318).
\end{abstract}

Ainda, durante esse período foram criadas as instituições para a educação ${ }^{1}$, na qual as crianças eram catequizadas conforme os costumes da Coroa Portuguesa, a fim de compreenderem a nova ordem que se estabelecia.

Verifica-se que a criança era usada conforme a necessidade dos adultos. Não possuindo proteção mínima de direitos.

Em 1830, foi realizada uma pequena alteração no Código Penal do Império, que introduziu o exame de capacidade de discernimento para aplicação de pena, sendo os menores de quatorze anos considerados inimputáveis. No entanto se houvesse discernimento na faixa de sete aos quatorze eram encaminhados para as casas de correção, segundo Amin (2010).

Posteriormente, é criado o primeiro Código Penal dos Estados Unidos do Brasil, que fazia pequenas alterações ao Código anterior. Eram considerados inimputáveis os menores de nove anos. E, quanto à verificação de discernimento, não houve alterações.

Apenas no século XVII o Estado passou a se preocupar com as crianças abandonadas. Era prática comum o abandono de crianças nas portas de igrejas, conventos, residências ou mesmo pelas ruas, de acordo com Amin (2010). Visando assistir essas crianças, foi instituído no Brasil a Roda dos Expostos. ${ }^{2}$

Segundo Marcílio (2001) a Roda dos Expostos, de origem Europeia, tinha como finalidade assistir as crianças abandonadas. Antes da instituição das rodas, os abandonados deveriam ser assistidos pelas câmaras municipais. Contudo, raramente assumiam a responsabilidade de cuidar das crianças.

Amin (2010) expõe que, além do abandono, no período republicano houve um aumento na população do Rio de Janeiro e de São Paulo, em virtude da migração dos escravos libertos. Assim, foi necessária a implantação de medidas que resolvessem as mazelas sociais como: doenças, fome, analfabetismo, delinquência, sem-teto. Para solucionar os problemas foram criadas entidades assistenciais com intuito higienistas ou de caridade.

\footnotetext{
1 As instituições para a educação de meninos surgiram no Brasil colonial com a ação educacional jesuítica, que implantou escolas elementares (de ler, escrever e contar) para crianças pequenas das aldeias indígenas e vilarejos, e criou colégios para a formação de religiosos e instrução superior de filhos das camadas mais privilegiadas da população.

${ }^{2} \mathrm{O}$ sistema de rodas de expostos foi inventado na Europa medieval. Seria ele um meio encontrado para garantir o anonimato do expositor e assim estimulá-lo a levar o bebê que não desejava para a roda, em lugar de abandoná-lo pelos caminhos, bosques, lixo, portas de igreja ou de casas de família, como era o costume, na falta de outra opção. Assim procedendo, a maioria das criancinhas morriam de fome, de frio ou mesmo comidas por animais, antes de serem encontradas e recolhidas por almas caridosas. (MARCÍLIO, 2001, pag.51-52).
} 
Artigo: Os princípios do contraditório e da ampla defesa nas medidas de proteção à luz do Estatuto da Criança e do Adolescente

O pensamento social oscilava entre assegurar direitos ou "se defender" dos menores. Casas de recolhimento são inauguradas em 1906, dividindo-se em escolas de prevenção, cujo objetivo era regenerar menores em conflito com a lei. (AMIN, 2010, pag. 6).

No âmbito internacional, conforme Vieira (2010), em 1924, foi aprovada pela Liga das Nações a Declaração de Genebra, que é o primeiro instrumento internacional dedicado aos menores. No referido documento a criança é mero objeto de proteção.

No Brasil, somente em 12 de outubro de 1927 foi criado o Código de Menores, que tutelava apenas os abandonados ou delinquentes. Conforme Andrade (2018) a responsabilidade sobre os menores era do Estado, que aplicava os meios necessários para impedir a delinquência.

Ressalta-se que a Constituição de 1934 faz menção à defesa e proteção dos direitos da criança e do adolescente, contudo sem os declarar sujeitos de direito.

Em 1959, foi feita a Declaração Universal dos Direitos da Criança, que gerou a criação da doutrina da Proteção Integral. Sêda (2004) esclarece que, a partir da declaração a criança passou a ser vista como sujeito de direitos, como pessoa respeitada pelo que são em si mesmas, não mais submetidas à vontade e ação alheias ou consideradas como meros objetos. No entanto, a Declaração não possuía caráter coercitivo.

Durante o período do regime militar foi publicada a Lei $\mathrm{n}^{\circ} 6.697$, que, de acordo com Amin (2010) consolidou a doutrina da Situação Irregular.

\footnotetext{
Não era uma doutrina garantista, até porque não enunciava direitos, mas apenas prédefinia situações e determinava uma atuação de resultados. Agia-se apenas na consequência e não na causa do problema, "apagando-se incêndios". Era um Direito do Menor, ou seja, que agia sobre ele, como objeto de proteção e não como sujeito de direitos. Daí a grande dificuldade de, por exemplo, exigir do poder público construção de escolas, atendimento pré-natal, transporte escolar, direitos fundamentais que, por não encontrarem previsão no código menorista, não eram, em princípio, passíveis de tutela jurídica. (AMIN, 2010, p. 13).
}

Segundo Oliveira (2013) apenas com a promulgação da Constituição de 1988 a criança passou a ser sujeito de direitos, sendo titular de proteção e garantias. Há, portanto, a ruptura da Doutrina da Situação Irregular com a recepção da Doutrina de Proteção Integral.

Ressalta-se que o contexto mundial favoreceu para essa mudança de postura, haja vista que passou a ser mais importante o coletivo/social.

De acordo com Amin (2010) com a doutrina da proteção integral, há o rompimento dos preceitos estabelecidos e a absorção dos princípios da Convenção dos Direitos da Criança, passando a criança a ser titular de direitos fundamentais.

$\mathrm{O}$ art. 227 da Constituição Federal estabelece

É dever da família, da sociedade e do Estado assegurar à criança, ao adolescente e ao
jovem, com absoluta prioridade, o direito à vida, à saúde, à alimentação, à educação,
ao lazer, à profissionalização, à cultura, à dignidade, ao respeito, à liberdade e à
convivência familiar e comunitária, além de coloca-los a salvo de toda forma de
negligência, discriminação, exploração, violência, crueldade e opressão. (BRASIL,
1988).

Assim, todos passam a ser responsáveis por assegurar os direitos das crianças e dos adolescentes.

Logo após, em 1992, foi criado o Estatuto da Criança e do Adolescente que veio para consagrar a Doutrina da Proteção Integral. Verifica-se que a Convenção sobre os Direitos da 
Criança de 1990 influencia e fundamenta os direitos da criança e do adolescente previstos no código.

Todo este arcabouço jurídico, constituído a partir da Constituição de 1988, procura assegurar às crianças e adolescentes o acesso a políticas sociais básicas, como saúde e educação; à política de assistência social, em caso de risco e vulnerabilidade social; e à políticas de garantias de direitos, para as situações de ameaça ou violação de direitos. No entanto, para que os direitos preconizados pelo ECA e demais legislações sejam materializados na prática da proteção da infância e juventude, é preciso que o conjunto de políticas sociais destinadas a inclusão das crianças e adolescentes estejam em pleno funcionamento e suas ações sejam planejadas e pensadas no sentido de garantir a vivência do acesso aos direitos. (LIMA, Renata Mantovani de; POLI, Leonardo Macedo; JOSÉ, Fernanda. 2017, pag. 327).

Por fim, não basta tão somente a previsão dos direitos e garantias das crianças e dos adolescentes. É necessário que haja a efetivação dos direitos, pois é dever do Estado, dos pais e da sociedade salvaguarda-los.

É inegável que inúmeras foram as conquistas adquiridas em toda evolução dos direitos das crianças e dos adolescentes, contudo, a discussão atual se pauta na aplicação dos mesmos.

\subsection{Conceitos gerais}

Atualmente o ECA regulamenta a aplicabilidade das medidas protetivas, sendo todas as crianças e adolescentes amparadas por normas que visam garantir primordialmente seus direitos.

Segundo Tavares (2010) as medidas de proteção são ações ou programas que visam dar assistência à criança ou adolescente que se encontram em situação de risco ou que tenham praticado ato infracional, possuindo caráter assistencial.

Para Tavares (2010) medida protetiva se define como

[...] providencias que visam salvaguardar qualquer criança ou adolescente cujos direitos tenham sido violados ou estejam ameaçados de violação. São, portanto, instrumentos colocados à disposição dos agentes responsáveis pela proteção de crianças e dos adolescentes, em especial, dos conselheiros tutelares e da autoridade judiciaria a fim de garantir, no caso concreto, a efetividade dos direitos da população infanto-juvenil. (TAVARES, 2010, pag. 522-523).

As medidas protetivas estão elencadas no Livro II, Título II, art. 98 e ss. do ECA. E devem ser utilizadas em momentos que a criança ou o adolescente se encontrarem em situação de risco ou vulnerabilidade. Assim, é necessário que, no caso concreto, sejam analisadas as condições reais que se encontram.

O artigo 98 do ECA dispõe as situações em que podem ser aplicadas as medidas protetivas, sendo por ação ou omissão da sociedade ou do Estado, por falta, omissão ou abuso dos pais ou responsável ou em razão de sua conduta.

Portanto, o objetivo principal é proteger os direitos garantidos por lei às crianças e aos adolescentes, sendo assegurado a todas as crianças e adolescentes, independente de critérios pré-estabelecidos. Assim, é um importante instrumento para garantir a efetividade dos direitos a eles conferidos, de acordo com Tavares (2010).

A premissa para aplicação das medidas protetivas está no artigo acima citado. É necessário, portanto, que haja situação de risco social ou pessoal, sendo nesses casos necessária 
Artigo: Os princípios do contraditório e da ampla defesa nas medidas de proteção à luz do Estatuto da Criança e do Adolescente

a intervenção dos órgãos institucionais para garantir dos direitos das crianças e adolescentes que se encontram em tal situação.

Segundo Tavares (2010) o artigo estabelece que aqueles que têm a obrigação de proteção podem ser os que as colocam em risco. Primeiramente, prevê a ameaça ou violação de direitos em decorrência de ação ou omissão do Estado ou da sociedade. Em um segundo momento, estabelece que a criança ou adolescente pode ser vítima da falta, omissão ou abuso dos pais ou responsáveis. Por último, a própria conduta da criança ou adolescente, quando incompatível com as regras em sociedade, pode ser objeto de aplicação da medida protetiva.

Importante ressaltar que o artigo 229 da Constituição Federal, estabelece, ainda, os deveres dos pais, quais sejam, "dever de assistir, criar e educar os filhos menores, e os filhos maiores tem o dever de ajudar e amparar os pais na velhice, carência ou enfermidade."

Ainda, o Código Civil, no art. 1638, estabelece as causas de destituição do poder familiar que podem também ser fundamento para aplicação de medida protetiva, vez que em alguns casos é necessário averiguar se houve de fato a conduta prevista no artigo, para posteriormente ser ajuizada a ação de destituição do poder familiar.

$\mathrm{O}$ art. 99 do ECA admite a aplicação isolada ou cumulada das medidas protetivas, ainda, a substituição a qualquer tempo. Dessa forma, o legislador permite que as medidas sejam aplicadas conforme a necessidade do caso concreto, sem estabelecer previamente condições para a aplicação de determinadas medidas.

Por fim, o art. 100 do ECA estipula os princípios que devem reger a aplicação das medidas protetivas. Além de primar pela aplicação de medidas que analisem as necessidades pedagógicas e sempre que possível fortaleçam os vínculos familiares.

\subsubsection{Aplicação das medidas protetivas}

$\mathrm{O}$ art. 101 do ECA dispõe sobre medidas protetivas específicas que devem ser implementadas quanto verificadas ameaça ou violação de direitos. Importante destacar que o rol não é taxativo, haja vista que há casos que necessitam de uma atuação específica.

Segundo Tavares (2010) o Conselho Tutelar e o Poder Judiciário são os órgãos competentes para aplicarem as medidas de proteção. O próprio Estatuto limita a atuação dos órgãos, cabendo ao Conselho Tutelar implementar as medidas previstas nos incisos I ao VII do art. 101 do ECA, com exceção das hipóteses excepcionais e de urgência em que poderá encaminhar a criança para acolhimento, desde que observado o previsto do art. 93 do Estatuto. Cabe ao Juiz da Vara da Infância e Juventude, visto que é sua a competência para julgar as ações que envolvem crianças em situação de risco, aplicar as medidas de acolhimento institucional e familiar, e a colocação em família substituta.

Verificando-se o risco, o juiz pode aplicar as medidas de ofício, em procedimento simples, nas hipóteses dos incisos I a VI do art. 101 do EAC, ou por meio de procedimento contencioso, nas hipóteses dos incisos VII, VIII e IX. Nos casos de prática de ato infracional o juiz pode aplicar medidas protetivas cumuladas com medidas socioeducativas, com exceção as hipóteses de acolhimento institucional e familiar e colocação em família substituta.

De acordo com Rossato, Lépore e Cunha (2017) não cabe ao Conselho Tutelar executar as medidas protetivas, sendo esta função de responsabilidade das entidades de atendimento especializado. Lhe cabendo apenas aplicar e fiscalizar as medidas protetivas.

Segundo Tavares (2010) as medidas protetivas têm por função proteger a criança ou o adolescente em virtude de ter os seus direitos violados. Contudo, as medidas visam, ainda, fortalecer os vínculos familiares e comunitários, haja vista que a criança tem o direito de permanecer em sua família, só sendo admitido encaminhamento da mesma para família substitutiva, após esgotadas todas as tentativas de reinserção da mesma em sua família natural. 
Por fim, salienta Souza (2014) que cabe ao Estado, bem como à sociedade, promover esforços, programas, projetos e ações a fim de proteger integralmente os núcleos familiares. E apenas, não sendo possível em caráter excepcional e provisório, a proteção da família natural, devidamente fundamentados e esgotadas as medidas de proteção integral da criança, é que será incluída a criança ou o adolescente em família substituta.

Observa-se que a prioridade do ECA em estabelecer medidas protetivas a serem adotadas antes do encaminhamento a família substituta visam caracterizar o abrigamento e a colocação em família substituta como medidas eventuais e excepcionais.

Souza (2014) reforça que

Fora das situações emergenciais de proteção das crianças e adolescentes, nos restritos termos do art. 93 da Lei n 12010/09, somente caberá a institucionalização de crianças e adolescentes em abrigos, depois da demonstração fundamentada da insuficiência das políticas públicas e das medidas de proteção exauridas nas esferas governamentais protetivas, além dos demais cuidados específicos para o início das medidas. (SOUZA, 2014).

Na prática, o que se verifica é que, diante da ausência de programas, entidades e aplicação das medidas de proteção, o encaminhamento das crianças para o acolhimento institucional torna-se a primeira medida a ser tomada pelos conselheiros tutelares. Em grande parte dos casos as tentativas de superação das vulnerabilidades acontecem apenas após acolhimento das crianças.

\subsubsection{O procedimento das ações de medidas protetivas}

No que tange a aplicação de um procedimento específico nas medidas protetivas, verifica-se que não cuidou o legislador de estabelecer qual a norma procedimental a ser seguida.

No caso do acolhimento institucional, a aplicação da medida protetiva deve ser analisada pela autoridade judicial. Assim, observam-se vários tipos de aplicação das medidas protetivas que variam de acordo com a natureza da medida a ser aplicada. A classificação se distingue entre as medidas protetivas que importam em afastamento familiar e as medidas que não importam em afastamento familiar.

Nesrala (2019) expõe os procedimentos que incidem sobre a aplicação de Medidas de Proteção como sendo

\footnotetext{
a) procedimento administrativo extrajudicial, para as Medidas de Proteção que podem ser aplicadas diretamente pelo Conselho Tutelar (art. 101, I a VI do ECA/90); b) procedimentos de jurisdição voluntária de rito especial para a entrega espontânea (art. 19-A do ECA/90); c) procedimentos de jurisdição voluntária de rito comum (hipóteses de flexibilização procedimental para aquelas medidas de proteção que não importam o afastamento da criança ou adolescente de sua família de origem, previstas nos art. 101, I a VI e art. 153, caput, ECA/90); d) procedimento de jurisdição contenciosa de rito comum para aquelas que importam em afastamento litigioso da criança de sua família (art. 101, VI a IX, art. 153, parágrafo único e art. 130 do ECA). (NESRALA, 2019, pag. 154)
}

Assim, os parágrafos do art.101 do ECA ditam o procedimento e prazos a serem seguidos bem como os requisitos.

Para o presente trabalho a medida protetiva que carece maior detalhamento se refere ao procedimento de jurisdição contenciosa de rito comum, que tem por finalidade o afastamento da criança de sua família natural. 
Artigo: Os princípios do contraditório e da ampla defesa nas medidas de proteção à luz do Estatuto da Criança e do Adolescente

Para a determinação do afastamento da família de origem, em decorrência da aplicação do acolhimento institucional, é necessário que haja ordem judicial nesse sentido. Não há, contudo, a definição do prazo para a instauração do processo contencioso, por parte do Ministério Público, sendo recomendado que aguarde o envio dos relatórios institucionais.

Importante definir que o objetivo das medidas de proteção que retiram a criança do seu lar visam definir a situação fática em que o infante se encontra, para que seja possível afastar a situação de risco.

Contudo, o legislador não se preocupou em estabelecer o procedimento para a aplicação de medida de proteção de acolhimento institucional ou familiar. Assim, tendo em vista que não há procedimento da legislação especial e não há procedimento específico da parte especial do Código de Processo Civil, por força do art.152 do ECA/90, cumulado com artigos 318 e 1049 do CPC, deverá ser aplicado o procedimento comum.

Frisa-se que o afastamento da criança do seu seio familiar é medida extrema e não deve ser julgada sem citação das partes, oportunidade de defesa, saneamento, especificação de provas e sentença.

O que se verifica na prática são ações ajuizadas, muitas vezes, sem petição inicial, sem a citação dos genitores, sem a tentativa de superação das vulnerabilidades familiares, sem oitiva das partes e nem mesmo da criança. O princípio do melhor interesse não é obedecido. A criança é colocada em família substituta e o feito é arquivado ou suspenso em virtude de ação ajuizada de destituição do poder familiar ou adoção cumulada com destituição do poder familiar.

Assim, tendo em vista os prejuízos que são gerados ao inserir a criança em uma nova família e, após, em virtude de nulidades processuais, encaminhá-la para a família de origem, o princípio do melhor interesse é utilizado pelos tribunais para evitar graves prejuízos psicológicos nas crianças, mantendo-a em família substituta. Tal posicionamento só corrobora para que não haja mudanças acerca da realidade enfrentada.

\section{A NECESSIDADE DE UM EFETIVO CONTRADITÓRIO NAS MEDIDAS PROTETIVAS}

Com a criação do Estatuto da Criança e do Adolescente passou a reger no ordenamento jurídico a Doutrina da Proteção Integral, contudo o que se percebe nas medidas protetivas é a utilização da Doutrina da Situação Irregular.

No curso dos processos observa-se que as decisões proferidas possuem claros resquícios da Doutrina da Situação Irregular que ignoram os direitos e garantias estabelecidos na Constituição Federal e replicam os preceitos de proteção da criança, sem assegurar minimamente os seus direitos.

Franco (2014) reforça

Constatamos em nossa pesquisa que, neste momento, procedimento judicial é conduzido de maneira semelhante ao praticado no período histórico orientado pela 'situação irregular' e 'menorista', deixando de lado o devido processo legal e ferindo o direito ao contraditório e da ampla defesa. (FRANCO, 2014, p. 59).

Ademais, as medidas protetivas que determinam o afastamento da criança do seu lar tramitam sem a devida defesa dos genitores/responsáveis no processo. Não há espaço para sequer ser esclarecido o fato que ensejou no acolhimento do infante.

Frisa-se, ainda, que, muitas vezes, nas ações de medidas protetivas, as crianças são encaminhadas para família substituta, mesmo tendo a ação o objetivo de permitir a reinserção da criança no seu seio familiar e sem que seja possível superar as vulnerabilidades da família. 
Em nota técnica emitida pelo Ministério Público de Minas Gerais, CAOIJ No 1, 2012, é esclarecido que o afastamento definitivo da criança de sua família de origem será apenas nas hipóteses em que todas as tentativas de supressão de maus-tratos e de violência tenham sido tentadas. Não obstante, o afastamento é provisório, sendo definitivo, apenas após a decisão de destituição do poder familiar. Contudo, uma vez que a criança já esteja inserida em um novo ambiente familiar é improvável que a mesma retorne para o seio de sua família.

Outrossim, o Estado Democrático de Direito garante às partes o devido processo legal, em especial o direito ao contraditório e a ampla defesa, para que seja possível o acesso à justiça e a influência das partes nas decisões judiciais.

Ainda, visa garantir o respeito a Doutrina da Proteção Integral ao estabelecer meios para garantir que o melhor interesse da criança seja mantido.

Destaca-se que as medidas protetivas não possuem procedimento específico definido em Lei, sendo necessária a aplicação do devido processo legal para garantir os direitos e garantias constitucionais.

Franco (2014) vai além e sustenta que

A inexistência de um sistema procedimental que tipificaria as aplicações jurisdicionais obrigatórias acaba por intensificar a responsabilidade de atuação dos profissionais envolvidos, norteando suas práticas, que podem culminar numa interpretação inadequada - subjetiva e não objetiva - dos artigos 98, 100 e 101 do ECA. (FRANCO, 2014, p. 51).

Não obstante, o rol do artigo 101 do ECA não é taxativo, e muitas vezes por não haver a hipótese expressamente prevista a única possibilidade encontrada pelos agentes é a colocação da criança em acolhimento institucional. Assim, a medida protetiva é utilizada como regra e não como exceção, como é proposta na lei.

A falha no sistema acontece desde o procedimento administrativo, pois não é dada a oportunidade dos genitores de melhorarem sua condição antes do ajuizamento da ação e não é dada a oportunidade posteriormente de se defenderem no processo instaurado como de verificação.

Sendo assim, a verificação do fato que ensejou no acolhimento do infante acontece sem a devida defesa dos responsáveis sendo posteriormente os atos praticados nas medidas protetivas utilizados como prova emprestada no processo de Destituição Poder do Familiar.

Na nota técnica do Ministério Público de Minas Gerais, CAOIJ Nº1, 2012, é reforçada a gravidade da medida de suspensão do direito à convivência familiar

\footnotetext{
Note-se que aqui, dada a gravidade da medida, que enseja a supressão, ainda que provisória, do direito fundamental à convivência familiar, uma vez colocada em acolhimento uma criança ou adolescente, a ação de afastamento do convívio familiar deverá ser obrigatoriamente ajuizada pelo Ministério Público, haja vista a necessidade de se regularizar aquela situação e se elaborar o estudo psicossocial, que é o instrumento que dará amparo a qualquer outra ação que o Ministério Público for tomar no futuro, como a destituição do poder familiar.(NOTA TÉCNICA MP CAOIJ nº1, 2012).
}

É absurdo pensar na quantidade de direitos que foram suprimidos das crianças e de sua família, além das inúmeras ofensas aos princípios do ECA no que tange a convivência familiar.

Franco (2014) defende que

Este afastamento da criança ou do adolescente do convívio familiar - que é de competência exclusiva da autoridade judiciária - deve deflagrar (conforme o parágrafo 
Artigo: Os princípios do contraditório e da ampla defesa nas medidas de proteção à luz do Estatuto da Criança e do Adolescente

acima) um procedimento judicial contencioso, no qual seja garantido aos pais ou ao responsável legal o exercício do direito ao contraditório e do direito à ampla defesa em contraposição à determinação cautelar de acolhimento institucional que, em síntese, é uma interferência do Estado na vida de um particular. Este processo contencioso precisa seguir as regras normais do devido processo legal, estabelecidas na legislação processual vigente que baliza o trâmite regular de um processo de suspensão (ou extinção) do poder familiar. (FRANCO, 2014, p. 57).

Com efeito, o advento da Lei 12.010 de 2009 incluiu a previsão no art. 101, IX, do ECA, na qual a decisão de afastamento da criança e do adolescente do convívio familiar deverá ser prolatada em procedimento contraditório, mais precisamente nas situações de colocação em família substituta.

Após a superação da urgência do caso, há a necessidade de instauração do rito comum no procedimento de medida protetiva vez que será analisada a real situação do infante e seu possível encaminhamento para a família substituta.

Com fulcro no art.101, $\S 2^{\circ}$ e 153 , parágrafo único, do ECA, o procedimento a ser utilizado é o do procedimento comum, pois é o único que garante as partes o exercício do contraditório e da ampla defesa, bem como a citação, saneamento, produção de provas e sentença no processo.

Nesrala (2019) expõe o sentimento das famílias que são vítimas das ações de medida protetiva

O discurso das famílias que perderam seus filhos para o Estado é de que não tiveram acesso à justiça, embora muitas delas tenham participado formalmente dos processos, com a assistência da Defensoria Pública ou de advogado constituído. Não se sentem defendidas justamente porque não tiveram oportunidade de serem ouvidas pelo juiz, de ter suas testemunhas também ouvidas em juízo ou de produzir outras provas. Esse é o retrato do fracasso do acesso à justiça e à ordem jurídica justa. $\mathrm{O}$ acesso à justiça pode ser alcançado pela simples observância do devido processo legal e pela verdadeira extinção da figura do juiz de menores, protetor dos desvalidos. Mas o acesso à ordem jurídica justa só virá com o investimento prioritário em políticas transversais de assistência baseada na família e no seu fortalecimento. (NESRALA, 2019, p. 151).

Ademais, Vay, Glens, Schwikert, Oliveira (2016) relatam as consequências do prosseguimento das medidas protetivas para as crianças e família

Os prejuízos à família natural são evidentes, sendo que, concedida uma tutela antecipada no curso do processo, desacolhendo-se a criança para os pretendentes à adoção sem que a destituição tenha se operado, a consolidação do "tempo de experiência" entre criança/adolescente e pretendentes à adoção cria vínculos de afeto e afinidade, os quais são paulatinamente esgarçados em relação a sua família de origem, ainda que no final do processo se constate que, de fato, as razões ensejadoras da destituição do poder familiar não se verificaram. Em assim sendo, ou torce-se para que os pais realmente sejam "pessoas ruins" e que deram causa à destituição, tudo a ratificar o procedimento até então realizado, ou então não há o que ser feito em relação a eles, pois os vínculos formados entre criança e pretendentes à adoção são tão fortes que, "em sua homenagem", são suficientes para que a família natural se conforme com a situação já estabelecida, priorizando-se a manutenção da criança/adolescente na nova família. Tal cenário se acentua em se tratando de crianças de tenra idade que vão firmando laços de afeto e afinidade com os pretendentes à adoção sem que houvesse a possibilidade de firmá-los em relação à família natural. (VAY, GLENS, SCHWIKERT, OLIVEIRA, 2016, p.122). 
Diante do exposto verifica-se o quão importante é a necessidade do contraditório e da ampla defesa nas medidas de proteção. É insustentável que o processo continue a tramitar sem um procedimento específico, pois há prejuízos irremediáveis às partes, sendo essencial a instauração de um processo contencioso que respeite o princípio do devido processo legal.

Por fim, destaca-se que após a retirada da criança do convívio familiar e sua colocação em família substituta, o que se observa é o caráter quase definitivo da situação fática da criança, pois o princípio do melhor interesse da criança é utilizado como amparo para manutenção do infante em família substituta. Nenhuma nulidade do processo tem o condão de retornar com essa criança para o seio de sua família, sob a justificativa de que tal ato gerará mais danos à formação psicológica da criança.

\section{CONSIDERAÇÕES FINAIS}

Com base no que foi exposto, é possível perceber que os direitos das crianças e adolescentes no Brasil, apesar de garantidos constitucionalmente, ainda, precisam de efetividade, vez que não há aplicabilidade dos direitos em processos de medida de proteção.

Nesse contexto, verificou-se, ainda, que é adotado nos processos de medidas de proteção a teoria da situação irregular, doutrina esta que era aplicada nos casos em que a criança estava em situação de abandono ou delinquência e precisava de algum tipo de proteção na vigência do Código dos Menores. Apesar da instauração de uma nova doutrina, na prática nada mudou. Mesmo com princípios e artigos claros que asseguram os direitos de crianças e pais, os mesmos não possuem a opção de terem seus direitos respeitados.

Há omissão em todos os sentidos, como a ausência do acesso à justiça dos genitores, que não são citados na medida de proteção, nem sequer sendo chamados para esclarecer os fatos que culminaram no acolhimento institucional.

Os princípios do contraditório e da ampla defesa não são aplicados ao processo de medida de proteção em prol de um digno acesso das partes ao devido processo legal. Além de não possuir um rito especifico no ordenamento jurídico, possuem implicações gravíssimas, seja no acolhimento ou até mesmo na colocação em família substituta do infante.

Ademais, destaca-se que as consequências são irreversíveis, posto que além do processo ser posteriormente utilizado como prova emprestada nos autos da Destituição do Poder Familiar, uma vez que a criança é colocada em família substituta, apesar de todas as nulidades do feito, o princípio do melhor interesse é utilizado para justificar a manutenção da decisão.

Portanto, diante do apresentado, observa-se que a falta de aplicação dos princípios acarreta danos irreparáveis e ferem diretamente os direitos da criança e do adolescente, como também da família, além de reforçar uma doutrina que desde a promulgação da Constituição de 1988 já devia ter sido abolida nas ações de medida protetiva.

\section{REFERÊNCIAS}

ANDRADE, Fabio Santos de. História Social da Criança e do Adolescente em Situação de Risco no Brasil a Partir dos Marcos Legais e do Cotidiano. Disponível em: hhttp://www.periodicos.unir.br/index.php/EDUCA/article/view/1600. Acesso em: 29 abr. 2019.

BARACHO, José Alfredo de Oliveira. Teoria Geral do Processo Constitucional. Disponível em: https://pos.direito.ufmg.br/rbep/index.php/rbep/article/view/4. Acesso em: 29 abr. 2019. 
BRASIL. Constituição da República Federativa do Brasil. Disponível em: http://www.planalto.gov.br/ccivil_03/constituicao/constituicaocompilado.htm. Acesso em: 22 set. 2018 .

BRASIL. Código Civil, Lei 10.406, de 10 de janeiro de 2002. Disponível em: http://www.planalto.gov.br/ccivil_03/leis/2002/110406.htm. Acesso em: 22 set. 2018.

BRASIL. Código de Processo Civil, Lei no 13.105 de 16 de Março de 2015. Disponível em: http://www.planalto.gov.br/ccivil_03/_ato2015-2018/2015/lei/113105.htm. Acesso em: 22 set. 2018.

BRASIL. Lei $\mathbf{n}^{\mathbf{0}}$ 8.069 de julho de 1990. Dispõe sobre o Estatuto da Criança e do Adolescente e dá outras providências. Disponível em:

http://www.planalto.gov.br/ccivil_03/LEIS/L8069.htm. Acesso em: 23 set. 2018.

BRÊTAS, Ronaldo de Carvalho Dias. Processo Constitucional e Estado Democrático de Direito. Belo Horizonte: Del Rey, 2010.

Defensoria Pública do Estado de Minas Gerais. Nota técnica 001/2017.

DIDIER JR., Fredie. Curso de direito processual civil: introdução ao direito processual civil, parte geral e processo de conhecimento I. 17. ed. - Salvador: Ed. Jus Podivm, 2015.

FRANCO, James Alan dos Santos. O Direito do contraditório e da ampla defesa nas aplicações de medidas protetivas de acolhimento institucional na fase das audiências concentradas. Disponível em:

https://tede2.pucsp.br/bitstream/handle/17680/1/James\%20Alan\%20dos\%20Santos\%20Franc o.pdf. Acesso em: 23 abr. 2019.

JORGE, André Guilherme Lemos. A Efetividade dos Princípios Constitucionais do Contraditório e da Ampla Defesa no Inquérito Civil. Disponível em: http://livros01.livrosgratis.com.br/cp041079.pdf. Acesso em: 01 mai. 2019.

GONÇALVES, Aroldo Plínio. Técnica processual e teoria do processo. Rio de Janeiro: Aide, 1992.

LIMA, Renata Mantovani de; POLI, Leonardo Macedo; JOSÉ, Fernanda São. A Evolução Histórica dos Direitos da Criança e do Adolescente: da insignificância jurídica e social ao reconhecimento de direitos e garantias fundamentais. Rev. Bras. Polít. Públicas (Online), Brasília, v. 7, nº 2, 2017.

MACIEL, Katia Regina Ferreira lobo Andrade. Curso de Direito da Criança e do Adolescente. Ed. SaraivaJur. São Paulo. 2017.

MARCÍLIO, Maria Luísa. A roda dos expostos e a criança abandonada na história do Brasil 1726-1950. In: FREITAS, Marcos Cezar de. (Org). História social da infância no Brasil. São Paulo: Ed. Cortez, 2001. 
MAURO, Renata Giovanoni Di. Procedimentos Civis nos Estatuto da Criança e do Adolescente. Ed. Saraiva. São Paulo. 2017.

Ministério Público de Minas Gerais. Nota Técnica CAOIJ nº 1 , de 7 de fevereiro de 2012. Pedido de Providências/Afastamento do convívio familiar. Minas Gerais, 2012.

MORAIS, Alexandre de. Direito constitucional / Alexandre de Moraes. - 13. ed. - São Paulo: Atlas, 2003.

NESRALA, Daniele Bellettato. A governança aplicada ao Sistema de Garantia de Direitos de crianças e adolescentes: um instrumento de acesso à ordem jurídica justa. 2019. $186 \mathrm{f}$. Dissertação (mestrado) - Universidade Federal de Minas Gerais, Faculdade de Direito.

OLIVEIRA, Thalissa Corrêa de. Evolução histórica dos direitos da criança e do adolescente com ênfase no ordenamento jurídico brasileiro. Disponível em:

http://webcache.googleusercontent.com/search?q=cache:ZoQrPJQldi0J:revistas.faa.edu.br/ind ex.php/FDV/article/download/173/141/+\&cd=2\&hl=pt-BR\&ct=clnk\&gl=br. Acesso em: 15 mar. 2018.

ROSSATO, Luciano Alves; CUNHA, Rogério Sanches; LÉPORE, Paulo Eduardo. Estatuto da Criança e do Adolescente. $7^{\text {a }}$ Edição. São Paulo: Editora Saraiva, 2015.

SÊDA, Edson. A criança e os princípios gerais: A concepção da Cidadania segundo o Estatuto da Criança e do Adolescente. Edição Adês, Rio de Janeiro. $1^{\circ}$ Edição 2004

SOUZA, Jadir Cirqueira. A Convivência familiar e comunitária e o acolhimento institucional. São Paulo, Editora Pillares, 2014.

VAY, Giancarlo Silkunas, GLENS, Mathias, SCHWEIKERT, Peter Gabriel Molinari, OLIVEIRA, Safira Bonilha de. O Caminho Necessário do Processo de Adoção - Pela Proteção Integral dos Integral dos Direitos da Criança e do Adolescente. Revista Liberdades., Edição 22 maio/ Agosto 2016.

VIEIRA, Marcelo de Mello. Direito de crianças e de adolescentes à convivência familiar. Disponível em: http://www.bibliotecadigital.ufmg.br/dspace/handle/1843/BUBD-9HMH64.

Acesso em: 20 mar. 2019.

TAVARES, Patrícia Silveira, AMIN, Andréa Rodrigues. Curso de Direito da Criança e do Adolescente. Ed. Saraiva. São Paulo, 2010.

TAVARES, André Ramos. Curso de Direito Constitucional. Disponível em: http://noosfero.ucsal.br/articles/0010/3240/tavares-andr-ramos-curso-de-direitoconstitucional.pdf. Acesso em: 01 abr. 2019.

THEODORO JÚNIOR, Humberto. Curso de Direito Processual Civil - Teoria geral do direito processual civil, processo de conhecimento e procedimento comum - vol. I. 56. ed. rev., atual. e ampl. - Rio de Janeiro: Forense, 2015. 